\title{
Anti-ulcerogenic activity of the root bark extract of the African laburnum "Cassia sieberiana" and its effect on the anti-oxidant defence system in rats
}

Edmund T Nartey ${ }^{1 *}$, Mark Ofosuhene ${ }^{2}$ and Caleb M Agbale ${ }^{3}$

\begin{abstract}
Background: Despite the widespread use of roots of Cassia sieberiana in managing several health conditions including gastric ulcer disease, there is little scientific data to support the rational phytotherapeutics as an anti-ulcer agent. This paper reports an evaluation of the in vivo anti-oxidant properties of an aqueous root bark extract of C. sieberiana in experimental gastric ulcer rats in a bid to elucidate its mechanism of action.

Methods: Fisher $344\left(F_{344}\right)$ rats received pretreatment of $C$. sieberiana root bark extract $(500,750$, and $1000 \mathrm{mg} / \mathrm{kg}$ body wt.) for 7 days after which there was induction of gastric injury with absolute ethanol. The mean ulcer index (MUI) was calculated and serum total anti-oxidant level determined. Gastric mucosal tissues were prepared and the activity level of the enzymes superoxide dismutase (SOD), catalase (CAT), glutathione peroxidase (GPX) and myeloperoxidase (MPO) were measured together with the level of lipid hydroperoxides (LPO). Statistical difference between treatment groups was analysed using one-way analysis of variance (ANOVA) followed by Dunnett's post hoc $t$ test. Statistical significance was calculated at $\mathrm{P}<0.05$.
\end{abstract}

Results: The administration of ethanol triggered severe acute gastric ulcer and pretreatment with C. sieberiana root bark extract significantly and dose dependently protected against this effect. The root bark extract also dose dependently and significantly inhibited the ethanol induced decrease in activity levels of the enzymes SOD, CAT and GPx. The extract also inhibited the ethanol-induced decrease in level of serum total anti-oxidant capacity. The increase in ethanol-induced LPO level and MPO activity were also significantly and dose-dependently inhibited by the root bark extract.

Conclusions: The gastro-cytoprotective effect, inhibition of decrease in activity of gastric anti-oxidant enzymes and MPO as well as the inhibition of gastric LPO level suggests that one of the anti-ulcer mechanisms of $C$. sieberiana is the anti-oxidant property.

Keywords: Gastric ulcer, Cassia sieberiana, Superoxide dismutase, Catalase, Glutathione peroxidase, Lipid hydroperoxide, Myeloperoxidase

\footnotetext{
* Correspondence: etnartey@chs.edu.gh

${ }^{1}$ Centre for Tropical Clinical Pharmacology and Therapeutics, University of

Ghana Medical School, P.O. Box GP 4236, Accra, Ghana

Full list of author information is available at the end of the article
} 


\section{Background}

Gastric ulcer disease (GUD) is a common problem of the gastro-intestinal tract with increasing incidence and prevalence attributed to various factors including the widespread use of non-steroidal anti-inflammatory drugs (NSAIDs). GUD is reported to affect about 14.5 million people worldwide with a mortality of about 4.08 million [1]. Although the etiology of gastric ulcers is still debated, it is accepted that gastric ulcers are triggered by an imbalance between factors that damage and those that protect the stomach. Mucosal damage, an initial step in gastric ulcer development, has been known to be due to hypersecretion of $\mathrm{HCl}$ through $\mathrm{H}^{+}, \mathrm{K}^{+}$-ATPase action [2], harbouring of $H$. pylori on the damaged mucin layer [3], the blockade of the cyclooxygenase enzyme system by NSAIDs [4], and oxidative stress by reactive oxygen species.

Reactive oxygen species (ROS) and free radicals play an important role in the pathogenesis of several human diseases including GUD [5,6]. Various studies have also shown that the endogenous anti-oxidant defense enzymes play a principal role in eliminating ROS and free radicals generated from the action of factors that damage the stomach. An approach to manage GUD, therefore, is through the scavenging of ROS and the stimulation of the endogenous anti-oxidant enzymes in the stomach in addition to the other approaches like the inhibition of gastric $\mathrm{H}^{+}, \mathrm{K}^{+}$-ATPase and the elimination of $H$. pylori using antibiotics.

Cassia sieberiana (Cassia kotschyana Oliv.; Fam. Caesalpinaceae), is a savannah tree that grows to about $15 \mathrm{~m}$ tall and is commonly fairly cultivated because of its attractive blossom and curious fruits (commonly referred to as the African laburnum). C. sieberiana has a very wide range of phytotherapeutic application in Ghana including the use of its roots in the management of hernia, leprosy, indigestion and gastric ulcer [7]. Studies by Nartey et al. [8] reported that the aqueous root bark extract of $C$. sieberiana possesses gastro-cytoprotective, anti-secretory and ulcer healing properties with the suggestion that its anti-ulcerogenic activity may be due to inhibition of the $\mathrm{H}^{+}, \mathrm{K}^{+}$-ATPase proton pump and increase in activity of gastric anti-oxidative enzymes. In another study by Nartey et al. [9], the aqueous root bark extract was shown to possess in vitro free radical scavenging and anti-oxidant properties and could stimulate the production of gastric mucosal prostaglandins $E_{2}$ and $I_{2}$. The aim of this study was therefore to assess the gastro-cytoprotective effect of root bark extract of C. sieberiana in comparison with ranitidine in a model of ethanol-induced gastric ulcer in rats and to elicit the underlying in vivo anti-oxidative mechanisms. For this purpose, the role of the root bark extract in oxidative stress was studied by measuring changes in activity levels of superoxide dismutase (SOD), catalase (CAT) and glutathione peroxidase (GPx). In addition, the total anti-oxidant capacity of blood serum, the level of lipid peroxidation (LPO) and the activity level of myeloperoxidase (MPO) as a marker of neutrophil infiltration of the stomach homogenates were also measured.

\section{Methods}

\section{Preparation of root bark extract}

Fresh roots of C. sieberiana (Cassia kotschyana Oliv.) were obtained from the grounds of the University of Ghana, authenticated at the Ghana herbarium and prepared as previously described by Nartey et al. [8]. Briefly, chopped fresh root barks of C. sieberiana (750 g) were grounded and mixed with $1 \mathrm{~L}$ of water and left to stand for 24 hours. The resulting concoction was evaporated under reduced pressure with the rotary evaporator at $30^{\circ} \mathrm{C}$ and the concentrate freeze-dried to yield solid material which was stored at $4^{\circ} \mathrm{C}$ and used within 4 weeks of production.

\section{Animals}

Fisher $344\left(\mathrm{~F}_{344}\right)$ rats weighing $230.3 \pm 14.5 \mathrm{~g}$ (mean \pm S.D) of both sexes were used for the studies. They were raised on standard laboratory diet (GAFCO, Tema, Ghana). The animal experimentation described in this study was approved by the Scientific and Technical Committee of the Noguchi Memorial Institute for Medical Research (NMIMR) of the University of Ghana and was conducted in accordance with internationally accepted principles for laboratory animal use and care.

\section{Chemicals and reagents}

The enzyme immunoassay kits for total anti-oxidants (Item \# 709001), lipid hydroperoxide-LPO (Item \# 705002), superoxide dismutase-SOD (Item \# 706002), catalase-CAT (Item \# 707002) and glutathione peroxidase-GPx (Item \# 703102), were obtained from Cayman Chemical Company (Ann Arbor, U.S.A). Protein assay kit (Item \# 704002) was also obtained from Cayman Chemical Company (Ann Arbor, U.S.A). All other chemicals and reagents were obtained from Sigma-Aldrich Chemical Company, St. Louis, MO, U.S.A.

\section{Administration of plant extract and induction of gastric ulcers}

Different concentrations of C. sieberiana root bark extract (dissolved in water as vehicle) were administered by oral gavage to the different animal groups (six animals per group) at $12 \mathrm{~h}$ intervals in a total volume of 2 $\mathrm{mL}$ for 7 days. The concentration of the plant extract was determined based on the earlier report of Nartey et al. [8]. One hour after the last administration of the root bark extract and after overnight fasting, animals received absolute ethanol ( $1 \mathrm{~mL} / 200 \mathrm{~g}$ body weight) by 
the same route [10]. One hour after the administration of ethanol, the animals were euthanised and blood collected by cardiac puncture. Serum was separated and used for the determination of total anti-oxidant capacity. The stomachs were then removed, cut open along the greater curvature and flushed gently with lukewarm water. Thereafter, the gastric mucosa was observed for lesions with the aid of a magnifying glass and the severity of the mucosal lesions scored according to the method of Marhueda et al. [11]. The vehicle (water) and ranitidine $(50 \mathrm{mg} / \mathrm{kg}$ body weight) were administered similarly as the $C$. sieberiana root bark extract. The ulcer score for each animal was determined and the mean ulcer index (MUI) and percentage inhibition for each group calculated as follows:

$$
\begin{aligned}
\text { MUI } & =\frac{\text { Total ulcer score }}{\text { Number of rats ulcerated }} \\
\% \text { Inhibition } & =\frac{\text { MUI of ethanol treated }- \text { MUI of extract pretreated }}{\text { UI of ethanol treated }} \\
& \times 100
\end{aligned}
$$

\section{Total antioxidant capacity}

The capacity of total anti-oxidants in the serum was assayed as per instructions from Cayman Chemical Company (Ann Arbor, U.S.A). Briefly the blood was allowed to clot for $30 \mathrm{~min}$ and then centrifuged at 2,000 $\mathrm{g}$ for $15 \mathrm{~min}$ at $4^{\circ} \mathrm{C}$. The resulting supernatant was assayed for total anti-oxidant capacity using Cayman's anti-oxidant assay kit (Item \# 709001).

\section{Determination of LPO levels and anti-oxidant enzymes activities}

In other set of experiments, after euthanasia the stomachs were quickly removed, rinsed in phosphate buffered saline (PBS, pH 7.4) and weighed. The stomachs were then homogenized and centrifuged according to the standard procedures using ELISA kits from Cayman Chemical Company (Ann Arbor, U.S.A) and the supernatant assayed as per instructions for determination of LPO (Item \# 705002) and the activity of the anti-oxidant enzymes SOD (Item \# 706002), CAT (Item \# 707002) and GPx (Item \# 703102). Protein levels were estimated by protein assay kits (Item \# 704002) from Cayman Chemical Company (Ann Arbor, U.S.A).

\section{Determination of myeloperoxidase (MPO) activity}

In another set of experiment, immediately after euthanasia the stomachs were quickly removed, homogenized $(1: 10 \mathrm{wt} / \mathrm{vol})$ in $0.5 \%$ hexadecyltrimethyl ammonium bromide (Sigma-Aldrich Chemical Company, U.S.A) in $50 \mathrm{mmol}$ potassium phosphate buffer ( $\mathrm{pH}$ 6.0) and assayed by the method of Bradley et al. [12] as described by Tariq et al. [13]. MPO activity in gastric tissues was expressed as $\mu \mathrm{mol} / \mathrm{min} / \mathrm{mg}$ tissue.

\section{Statistical analysis}

Comparisons between means were performed using one-way analysis of variance (ANOVA) followed by Dunnett's post hoc $t$ test to determine statistical significance. $\mathrm{P}<0.05$ was considered significant.

\section{Results}

\section{Anti-ulcer activity}

The result of the effect of ethanol on ulcer index is shown in Table 1. Treatment of rats with absolute ethanol produced extensive gastric ulcers in the glandular mucosa of stomach in all of the control animals. The mean ulcer index (MUI) was found to be $8.00 \pm 0.37$ in control animals (Table 1). Pretreatment of rats with C. sieberiana root bark extract in the doses of $500 \mathrm{mg} /$ $\mathrm{kg}$ (MUI, $5.83 \pm 0.31$ ), $750 \mathrm{mg} / \mathrm{kg}$ (MUI, $4.00 \pm 0.37$ ), and $1000 \mathrm{mg} / \mathrm{kg}$ (MUI, $1.170 \pm 0.17$ ) for 7 days significantly and dose-dependently inhibited the formation of gastric lesions $(\mathrm{p}<0.001)$. There were $27.50 \%, 50.00 \%$ and $85.38 \%$ protection in the CS-500, CS-750 and CS-1000 groups respectively (Figure 1). There was no significant difference ( $p>0.05$ ) in ulcer inhibition between the ranitidine pre-treated control group (81.25\%) and the CS-1000 group (85.38\%).

\section{Lipid peroxidation index}

Table 2 shows that treatment of animals with absolute ethanol induced the generation of significant amounts $(\mathrm{p}<0.001)$ of LPO from $2.85 \pm 0.17 \mathrm{nmol} / \mathrm{mg}$ protein in the baseline (intact) to $8.34 \pm 0.13 \mathrm{nmol} / \mathrm{mg}$ protein in the ulcer control. Administration of the plant extract significantly $(p<0.001)$ inhibited the generation of lipid hydroperoxides in a dose-dependent manner. The high dose of C. sieberiana (CS-1000) inhibited the generation of LPO from $8.34 \pm 0.13 \mathrm{nmol} / \mathrm{mg}$ protein in the ulcer control to $3.13 \pm 0.13 \mathrm{nmol} / \mathrm{mg}$ protein which was significantly higher $(\mathrm{p}<0.001)$ than the effect of ranitidine $(5.09 \pm 0.06 \mathrm{nmol} / \mathrm{mg}$ protein $)$.

\section{MPO activity}

Table 2 shows that the activity of gastric MPO was significantly increased $(\mathrm{p}<0.001)$ from $2.80 \pm 0.20 \mu \mathrm{mol} /$ $\mathrm{min} / \mathrm{mg}$ tissue in the baseline (intact) group to $9.20 \pm$ $0.26 \mu \mathrm{mol} / \mathrm{min} / \mathrm{mg}$ tissue when the rats were administered ethanol. Pre-treatment with different doses of the extract significantly $(\mathrm{p}<0.001)$ attenuated ethanolinduced increase in gastric MPO activity in rats in a dose-dependent manner which was similar to the effect of ranitidine. However the effect of the high dose of $C$. sieberiana root bark extract (CS-1000) (3.27 \pm 0.10 $\mu \mathrm{mol} / \mathrm{min} / \mathrm{mg}$ tissue $)$ was significantly higher $(\mathrm{p}<0.001)$ 
Table 1 Effect of $C$. sieberiana (CS) root bark extract on ulcer index in ethanol-induced gastric ulcer rats

\begin{tabular}{lll}
\hline Treatment & $\begin{array}{l}\text { Dose } \\
\text { (mg/kg body wt.) }\end{array}$ & $\begin{array}{l}\text { Mean Ulcer index } \\
\text { [Score 0-10](Mean } \pm \text { SEM) }\end{array}$ \\
\hline Baseline (intact) & - & - \\
Ulcer control & Vehicle & $8.00 \pm 0.37$ \\
CS-extract & 500 & $5.80 \pm 0.31^{\mathrm{a}}$ \\
" & 750 & $4.00 \pm 0.37^{\mathrm{b}, \mathrm{c}}$ \\
" & 1000 & $1.17 \pm 0.17^{\mathrm{b}, \mathrm{d}}$ \\
Ranitidine & 50 & $1.50 \pm 0.22^{\mathrm{b}}$ \\
\hline
\end{tabular}

${ }^{a} p<0.05$ compared with ulcer control; ${ }^{b} p<0.001$ compared with ulcer control; ${ }^{c} p<0.05$ compared with CS-500; ${ }^{d} p<0.01$ compared with CS-750; Values are Mean \pm SEM of 6 animals. Statistical significance was determined by one-way analysis of variance (ANOVA) followed by Dunnett's post hoc $t$ test.

than that of ranitidine $(4.22 \pm 0.08 \mu \mathrm{mol} / \mathrm{min} / \mathrm{mg}$ tissue $)$, the reference anti-ulcer agent.

\section{Serum total anti-oxidant capacity}

The results in Figure 2 show the effect of treatments on total anti-oxidant capacity in serum. Analysis of the results indicates that untreated animals induced with gastric ulcer showed a significant decrease $(\mathrm{p}<0.001)$ in serum total anti-oxidants $(1.93 \pm 0.07 \mu \mathrm{mol} / \mathrm{mg}$ protein $)$ when compared with the intact gastric mucosa (4.76 \pm $0.04 \mu \mathrm{mol} / \mathrm{mg}$ protein). Animals pre-treated with ranitidine and extract at the three tested doses showed a significant dose-dependent increase in total serum antioxidants. This improvement was most pronounced $(4.77 \pm 0.07 \mu \mathrm{mol} / \mathrm{mg}$ protein $)$ in the group that received the high dose of $C$. sieberiana root bark extract (CS-1000). Pre-treatment of animals with ranitidine, the standard anti-ulcer drug showed significantly lower total serum anti-oxidant capacity compared with CS-1000 $(\mathrm{p}<0.01)$.

\section{SOD activity}

The results in Figure 3 represent the effect of various treatments on SOD activity. Analysis of the figure shows that the activity of SOD was significantly lowered $(\mathrm{p}<0.001)$ in the gastric mucosa of animals exposed to ethanol (Ulcer control) (2.56 $\pm 0.11 \mathrm{U} / \mathrm{mg}$ protein), when compared with the respective value in intact gastric mucosa (baseline) (5.80 $\pm 0.06 \mathrm{U} / \mathrm{mg}$ protein). Pretreatment of the rats with $C$. sieberiana for 7 days showed a dose-dependent significant $(\mathrm{p}<0.001)$ inhibition of the effect of ethanol in decreasing SOD. Pre-treatment with ranitidine also showed a significant $(p<0.001)$ inhibition of the effect of ethanol on gastric mucosal SOD but this was lower $(\mathrm{p}<0.01)$ than the effect of CS-1000.

\section{CAT activity}

The results of the effect of different treatments on catalase activity are shown in Figure 4 . The activity of catalase in gastric mucosa significantly varied after ethanol treatment, decreasing from $7.67 \pm 0.16 \mathrm{nmol} / \mathrm{min} / \mathrm{mg}$ protein in the baseline (intact) group to $4.64 \pm 0.08$ $\mathrm{nmol} / \mathrm{min} / \mathrm{mg}$ protein in the group exposed to ethanol (Ulcer control). Figure 4 also shows that pre-treatment of the animals with different doses of the root bark extract for 7 days significantly inhibited the effect of the ethanol on CAT in a dose-dependent manner. Rats administered $1000 \mathrm{mg} / \mathrm{kg}$ bd. weight of the extract significantly increased $(\mathrm{p}<0.001)$ CAT activity from $4.64 \pm$ $0.08 \mathrm{nmol} / \mathrm{min} / \mathrm{mg}$ protein in the ulcer control to $7.76 \pm$ $0.08 \mathrm{nmol} / \mathrm{min} / \mathrm{mg}$ protein in CS-1000. This increase in CAT activity was significantly higher $(\mathrm{p}<0.001)$ than that recorded for ranitidine $(6.27 \pm 0.05 \mathrm{nmol} / \mathrm{min} / \mathrm{mg}$ protein).

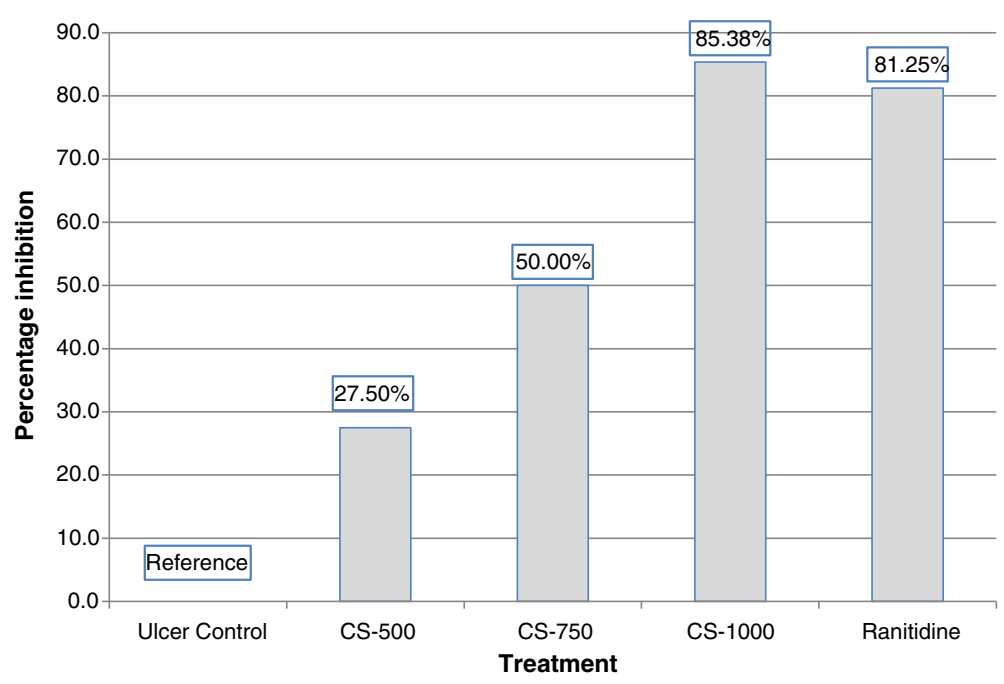

Figure 1 Effect of $C$. sieberiana (CS) root bark extract on gastric ulcer inhibition in $\mathrm{F}_{344}$ rats. 
Table 2 Effect of $C$. sieberiana (CS) root bark extract on lipid peroxidation indices in ethanol-induced gastric ulcer rats

\begin{tabular}{llll}
\hline Treatment & Dose $(\mathbf{m g} / \mathbf{k g}$ body $\mathbf{w t})$. & LPO $(\mathbf{n m o l} / \mathbf{m g}$ protein) & MPO $(\boldsymbol{\mu m o l} / \mathbf{m i n} / \mathbf{m g}$ tissue $)$ \\
\hline Baseline (intact) & - & $2.85 \pm 0.17$ & $2.80 \pm 0.20$ \\
Ulcer control & Vehicle & $8.34 \pm 0.13^{\mathrm{a}}$ & $9.20 \pm 0.26^{\mathrm{a}}$ \\
CS-extract & 500 & $6.68 \pm 0.11^{\mathrm{b}}$ & $6.13 \pm 0.27^{\mathrm{b}}$ \\
$"$ " & 750 & $5.30 \pm 0.15^{\mathrm{b}, \mathrm{c}}$ & $4.49 \pm 0.12^{\mathrm{b}, \mathrm{f}}$ \\
" & 1000 & $3.13 \pm 0.17^{\mathrm{b}, \mathrm{d}}$ & $3.27 \pm 0.10^{\mathrm{b}, \mathrm{d}}$ \\
Ranitidine & 50 & $5.09 \pm 0.06^{\mathrm{b}, \mathrm{e}}$ & $4.22 \pm 0.08^{\mathrm{b}, \mathrm{e}}$
\end{tabular}

${ }^{a} p<0.001$ compared with baseline; ${ }^{b} p<0.001$ compared with ulcer control; ${ }^{c} p<0.001$ compared with CS-500; ${ }^{d} p<0.001$ compared with CS-750; ${ }^{e} p<0.001$ compared with CS-1000; ${ }^{f} p<0.05$ compared with CS-500; Values are Mean \pm SEM of 6 animals. Statistical significance was determined by one-way analysis of variance (ANOVA) followed by Dunnett's post hoc $t$ test.

\section{GPx activity}

The effect of the extract and ranitidine, a reference compound on the activity of GPx are shown in Figure 5. The graph shows that the administration of ethanol significantly reduced $(\mathrm{p}<0.001)$ the activity of GPx from 3.75 $\pm 0.16 \mathrm{nmol} / \mathrm{min} / \mathrm{mg}$ protein in the baseline (intact) to $1.57 \pm 0.16 \mathrm{nmol} / \mathrm{min} / \mathrm{mg}$ protein in the ulcer control. All three doses of $C$. sieberiana significantly inhibited the effect of ethanol on GPx compared with the ulcer control. The CS-1000 succeeded in inducing a significant improvement $(\mathrm{p}<0.001)$ in GPx activity compared with the ulcer control and this effect was similar but significantly higher $(\mathrm{p}<0.01)$ to that of ranitidine.

\section{Discussion}

Gastric ulcer disease is a multi-factorial disease and the significant role played by reactive oxygen species and free radicals [5] during its pathogenesis is well experimented in both human and experimental animals [14].
The administration of absolute ethanol in the induction of gastric ulcer in experimental rats is one of several methods used in the assessment of the gastro- cytoprotective action of anti-ulcer agents. The injurious effect of absolute ethanol in the stomach as a result of superficial aggressive necrosis due to enhanced lipid peroxidation also involves various mediators like lipoxygenase, cytokines [15], and excessive generation of oxygen-derived free radicals [16].

The present study was undertaken to investigate the in-vivo anti-oxidant effect of the root bark extract of C. sieberiana in a model of ethanol-induced gastric ulcer in rats. The results of the present study indicates that oral administration of $C$. sieberiana root bark extract had a significant and dose-dependent increase of the MUI inhibition (percent) against ethanol-induced gastric lesions (Figure 1). Compared with the untreated ulcer control animals, the inhibition of the gastric ulcers were $27.50 \%, 50.00 \%$ and $85.38 \%$ respectively for animals

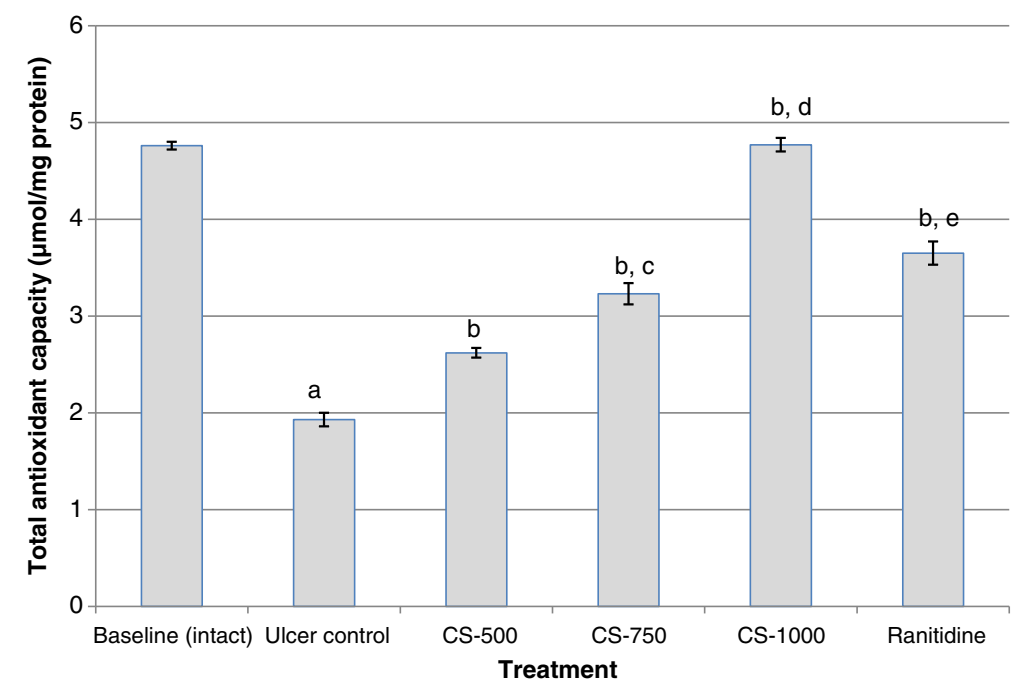

Figure 2 Effect of $C$. sieberiana (CS) plant extract on serum total anti-oxidant capacity in $F_{344}$ rats. ${ }^{a} p<0.001$ compared with baseline (intact); ${ }^{b} p<0.001$ compared with ulcer control; ${ }^{c} p<0.05$ compared with CS-500; ${ }^{d} p<0.001$ compared with CS-750; ${ }^{e} p<0.01$ compared with CS-1000; Values are Mean \pm SEM of 6 animals. Statistical significance was determined by one-way analysis of variance (ANOVA) followed by Dunnett's post hoc $t$ test. 


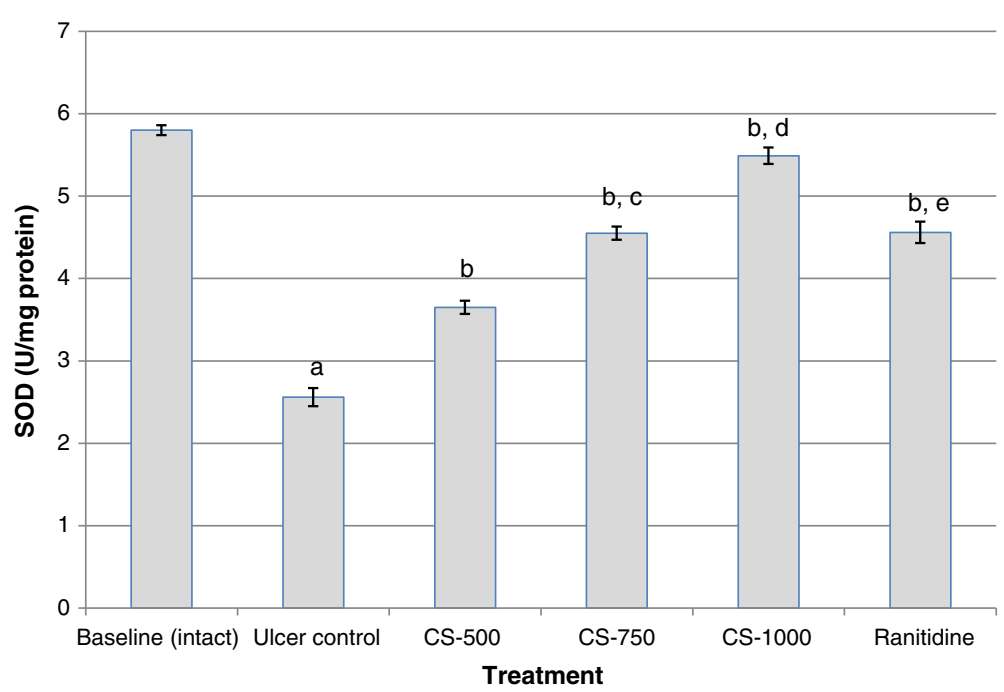

Figure 3 Effect of $C$. sieberiana (CS) plant extract on mucosal superoxide dismutase activity in $F_{344}$ rats. ${ }^{a} p<0.001$ compared with baseline (intact); ${ }^{b} p<0.001$ compared with ulcer control; ${ }^{c} p<0.001$ compared with CS-500; ${ }^{d} p<0.001$ compared with CS-750; ${ }^{e} p<0.01$ compared with CS-1000; Values are Mean \pm SEM of 6 animals. Statistical significance was determined by one-way analysis of variance (ANOVA) followed by Dunnett's post hoc $t$ test.

pretreated with $500 \mathrm{mg} / \mathrm{kg}, 750 \mathrm{mg} / \mathrm{kg}$ and $1000 \mathrm{mg} / \mathrm{kg}$ body weight of C. sieberiana. This data suggests that $C$. sieberiana root bark extract possesses strong gastrocytoprotective properties against ethanol-induced gastric ulcers. This is in agreement with earlier reports that the root bark extract possesses anti-ulcerogenic properties in other induced gastric ulcer animal models [8] and is supported by the inhibition of decrease of the antioxidative enzymes SOD, CAT and GPx.
The endogenous anti-oxidant enzymes SOD, CAT and GPx in the gastric mucus are the key component of cellular defense system against reactive oxygen species. SOD catalyses the dismutation of $\mathrm{O}_{2}^{-}$to $\mathrm{H}_{2} \mathrm{O}_{2}$ which is then scavenged by CAT and GPx. The activity of GPx leads to the elimination of lipid hydroperoxides and hence plays an important role in cell protection [17]. Thus, inhibition of the activities of these enzymes in the gastric mucosa by ethanol may result in the accumulation of hydrogen

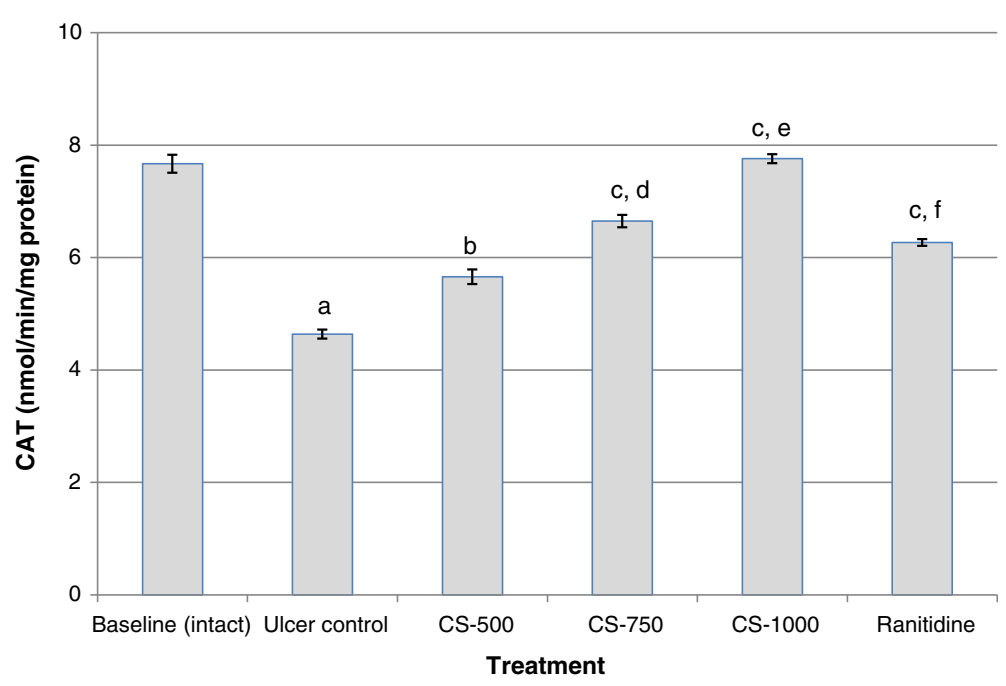

Figure 4 Effect of $C$. sieberiana (CS) plant extract on mucosal catalase activity in $\mathbf{F}_{344}$ rats. ${ }^{a} p<0.001$ compared with baseline (intact); ${ }^{b}$

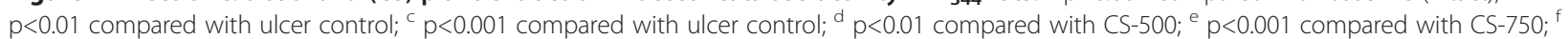
$p<0.001$ compared with CS-1000; Values are Mean \pm SEM of 6 animals. Statistical significance was determined by one-way analysis of variance (ANOVA) followed by Dunnett's post hoc $t$ test. 


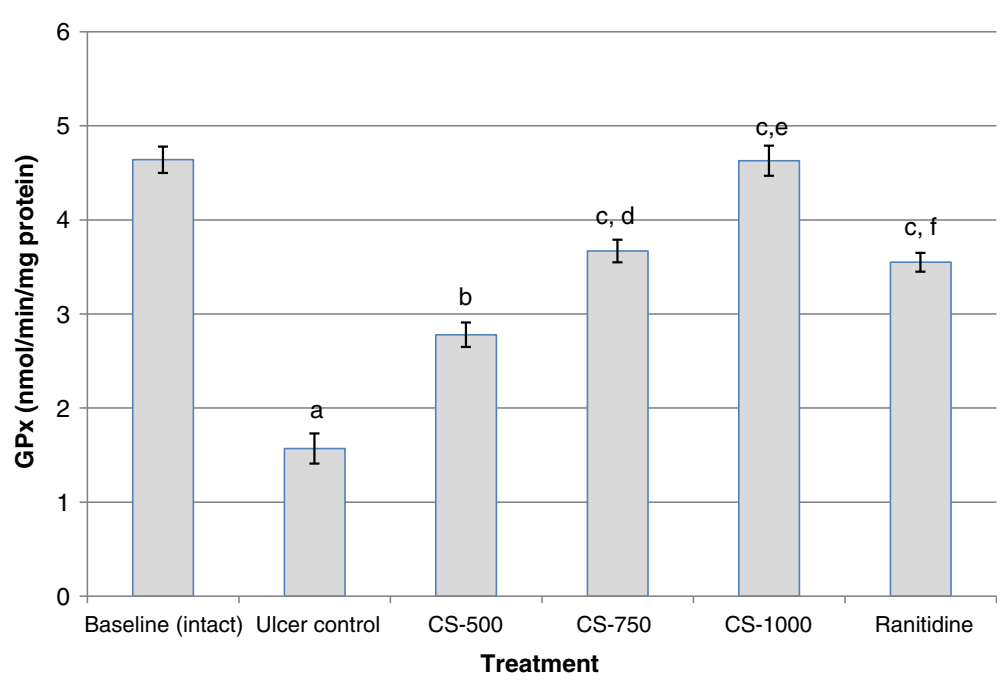

Figure 5 Effect of $\boldsymbol{C}$. sieberiana (CS) plant extract on mucosal glutathione peroxidase activity in $\mathbf{F}_{344}$ rats. ${ }^{a} p<0.001$ compared with baseline (intact); ${ }^{b} p<0.01$ compared with ulcer control; ${ }^{c} p<0.001$ compared with ulcer control; ${ }^{d} p<0.01$ compared with CS-500; ${ }^{e} p<0.05$ compared with CS-750; ${ }^{f} p<0.01$ compared with CS-1000; Values are Mean \pm SEM of 6 animals. Statistical significance was determined by one-way analysis of variance (ANOVA) followed by Dunnett's post hoc $t$ test.

peroxide with subsequent oxidation of lipids which will ultimately lead to loss of membrane integrity. Results from this study indicate that ethanol administration significantly decreased $(\mathrm{p}<0.001)$ the activities of SOD, CAT and GPx and also serum total anti-oxidant capacity when compared with the un-ulcerated baseline animals. This observation was made $1 \mathrm{~h}$ after absolute ethanol administration. A decrease of SOD, CAT and GPx activities in gastric mucosa of rats exposed to ethanol leads to the accumulation of ROS and consequently to an increase in lipid peroxidation concentration and hence an increased mucosal damage as seen from the increase in MUI. These observations confirm the findings of several studies, which reported alterations in anti-oxidant enzyme activities in ethanol exposed animals [18-22]. The dose-dependent inhibition of ethanol-induced decrease in activity levels of gastric SOD, CAT and GPx when the animals where pretreated with $C$. sieberiana indicates that the root bark extract contains bioactive substances which can stimulate the activity of the endogenous gastric antioxidant enzyme system. The induced activity of the antioxidant defence system was supported by an increase in serum total antioxidant capacity, decrease in lipid hydroperoxides (LPO) and inhibition of myeloperoxidase (MPO) activity.

Induced SOD, CAT and GPx activities explains the decrease in LPO from $8.34 \pm 0.13 \mathrm{nmol} / \mathrm{mg}$ protein in the ulcer control to $3.13 \pm 0.13 \mathrm{nmol} / \mathrm{mg}$ protein in CS1000 which is in correlation with the maintenance of baseline (intact) enzyme activity levels of SOD, CAT and GPx ( $>>0.05)$. The gastro-cytoprotective effect of the root bark extract was also accompanied by inhibition of ethanol-induced increase in MPO from 9.20 \pm 0.26 $\mu \mathrm{mol} / \mathrm{min} / \mathrm{mg}$ tissue in the ulcer control to $3.27 \pm 0.10$ $\mu \mathrm{mol} / \mathrm{min} / \mathrm{mg}$ tissue in CS-1000. The MPO assay is widely used as an index of neutrophil infiltration in various gastric ulcer models [23-25]. Neutrophils are the major inflammatory cell type infiltrating the injured mucosa following exposure to ethanol [26] and strategies to counteract the infiltration and/or activation of neutrophils have been shown to protect animals against gastric ulcers [27]. The effect of C. sieberiana in inhibiting an increase of MPO activity may therefore be related to its gastro-cytoprotective ability. This inhibition of neutrophil activation is in agreement with earlier studies that the root bark extract has anti-inflammatory properties $[9,28]$.

The in-vivo anti-oxidant property of C. sieberiana root bark extract demonstrated in this study may be due to the presence of flavonol/flavonoid/flavone or related compounds with polyhydroxy and/or phenolic groups which we had earlier detected by phytochemical analysis [9]. Further studies we previously conducted [9] demonstrated that TLC spots revealed by fluorescence under UV light and their reaction with ferric chloride suggest that flavonol/flavonoid/flavone or related compounds with polyhydroxy and/or phenolic groups constituted major chemical substances in the root bark extract. Flavonoids or polyphenolic substances quench ROS, chelate metal ions and regenerate membrane-bound anti-oxidants and it has been demonstrated that substances with anti-oxidant properties, such as polyphenolic compounds, may protect against gastric-damaging effects caused by ethanol [29-35]. 


\section{Conclusion}

In conclusion, the present results suggest that the gastrocytoprotective effect of C. sieberiana root bark extract against mucosal injury induced by ethanol might be mediated at least partially by its ability to stimulate and thereby maintain baseline activity level of mucosal antioxidant enzymes such as SOD, CAT and GPx which constitute endogenous scavengers of ROS. This effect is supported by the elevation of serum total anti-oxidant level and the inhibition of increase in LPO in addition to the inhibition of MPO enzyme activity to maintain them at near basal level.

\section{Abbreviations}

CS: Cassia sieberiana; CAT: Catalase; F 344 : Fisher 344; GPX: Glutathione peroxidase; LPO: Lipid hydroperoxide; MPO: Myeloperoxidase; MUI: Mean ulcer index; ROS: Reactive oxygen species; SOD: Superoxide dismutase.

\section{Competing interests}

The authors declare they have no competing interests.

\section{Authors' contributions}

ETN and MO worked in the conception, methods, analysing results and revising it critically. CMA worked on the methods, data analysis and revising it critically. All three authors read and approved the final manuscript.

\section{Author details}

${ }^{1}$ Centre for Tropical Clinical Pharmacology and Therapeutics, University of Ghana Medical School, P.O. Box GP 4236, Accra, Ghana. ²Department of Clinical Pathology, Noguchi Memorial Institute for Medical Research, University of Ghana, P. O. Box LG 581, Legon, Ghana. ${ }^{3}$ Department of Biochemistry, School of Biological Sciences, University of Cape Coast, Cape Coast, Ghana.

Received: 17 August 2012 Accepted: 7 December 2012 Published: 10 December 2012

\section{References}

1. Srikanta BM, Siddaraju MN, Dharmesh SM: A novel phenol-bound pectic polysaccharide from Decalepis hamiltonii with multi-step ulcer preventive activity. World J Gastroenterol 2007, 13(39):5196-5207.

2. Phull PS, Green CJ, Jacyna MR: A radical view of the stomach: the role of oxygen-derived free radicals and anti-oxidants in gastroduodenal disease. Eur J Gastroenterol Hepatol 1995, 7(3):265-274.

3. Odenbreit S: Adherence properties of Helicobacter pylori: impact on pathogenesis and adaptation to the host. Int J Med Microbiol 2005, 295(5):317-324.

4. Khanna S, Madan M, Vangoori A, Banerjee R, Thaimattam R, Jafar Sadik Basha SK, Ramesh M, Casturi SR, Pal M: Evaluation of glycolamide esters of indomethacin as potential cyclooxygenase-2 (COX-2) inhibitors. Bioorg Med Chem 2006, 14:4820-4833.

5. Repetto MG, Llesuy SF: Antioxidant properties of natural compounds used in popular medicine for gastric ulcers. Braz I Med Biol Res 2002 35(5):523-534

6. Gulcin I: Antioxidant activity of food constituents: an overview. Arch Toxicol 2012, 86(3):345-391.

7. Abbiw DK: Portions and Medicine, Useful plants of Ghana. London: Intermediate Technology Publications; 1990:118-205.

8. Nartey ET, Addo PG, Ofosuhene M, Okine LK, Nyarko AK: The effect of Cassia sieberiana root bark extract on various experimental gastric ulcer models in rats. J Phytomed Ther 2009, 14:53-59.

9. Nartey ET, Ofosuhene M, Kudzi W, Agbale CM: Antioxidant and gastric cytoprotective prostaglandins properties of Cassia sieberiana roots bark extract as an anti-ulcerogenic agent. BMC Complement Altern Med 2012. 12(1):65.

10. Natale G, Lazzeri G, Blandizzi C, Gherardi G, Lenzi P, Pellegrini A, Del Tacca $\mathrm{M}$ : Seriate histomorphometry of whole rat stomach: an accurate and reliable method for quantitative analysis of mucosal damage. Toxicol Appl Pharmacol 2001, 174(1):17-26.

11. Marhueda E, Martin MJ, de Alarcon lastra C: Antiulcerogenic activity of aescine in different experimental models. Phytother Res 1993, 7:13-16.

12. Bradley PP, Priebat DA, Christensen RD, Rothstein G: Measurement of cutaneous inflammation: estimation of neutrophil content with an enzyme marker. J Invest Dermatol 1982, 78(3):206-209.

13. Tariq M, Khan HA, Elfaki I, Arshaduddin M, Al Moutaery M, Al Rayes $\mathrm{H}$, Al Swailam R: Gastric antisecretory and antiulcer effects of simvastatin in rats. J Gastroenterol Hepatol 2007, 22(12):2316-2323.

14. Rao CV, Maiti RN, Goel RK: Effect of mild irritant on gastric mucosal offensive and defensive factors. Indian J Physiol Pharmacol 2000, 44(2):185-191.

15. Nordmann R, Ribiere $C$, Rouach H: Implication of free radical mechanisms in ethanol-induced cellular injury. Free Radic Biol Med 1992, 12(3):219-240

16. Abdel-Salam OM, Czimmer J, Debreceni A, Szolcsanyi J, Mozsik G: Gastric mucosal integrity: gastric mucosal blood flow and microcirculation. An overview. J Physiol Paris 2001, 95(1-6):105-127.

17. Halliwell B: Reactive oxygen species in living systems: source, biochemistry, and role in human disease. Am J Med 1991, 91(3C):14S-22S.

18. Khosla P, Karan RS, Bhargava VK: Effect of garlic oil on ethanol induced gastric ulcers in rats. Phytother Res 2004, 18(1):87-91.

19. Bafna PA, Balaraman R: Anti-ulcer and antioxidant activity of DHC-1, a herbal formulation. J Ethnopharmacol 2004, 90(1):123-127.

20. Alvarez-Suarez JM, Dekanski D, Ristic S, Radonjic NV, Petronijevic ND, Giampieri F, Astolfi P, Gonzalez-Paramas AM, Santos-Buelga C, Tulipani S, et al: Strawberry polyphenols attenuate ethanol-induced gastric lesions in rats by activation of antioxidant enzymes and attenuation of MDA increase. PLoS One 2011, 6(10):e25878.

21. Alirezaei M, Dezfoulian O, Neamati S, Rashidipour M, Tanideh N, Kheradmand A: Oleuropein prevents ethanol-induced gastric ulcers via elevation of antioxidant enzyme activities in rats. J Physiol Biochem 2012 doi:10.1007/s13105-13012-10177-13108.

22. de Faria FM, Almeida AC, Luiz-Ferreira A, Takayama C, Dunder RJ, da Silva MA, Salvador MJ, Abdelnur PV, Eberlin MN, Vilegas W, et al: Antioxidant Action of Mangrove Polyphenols against Gastric Damage Induced by Absolute Ethanol and Ischemia-Reperfusion in the Rat. ScientificWorldJournal 2012, 32:70-71.

23. Odabasoglu F, Cakir A, Suleyman H, Aslan A, Bayir Y, Halici M, Kazaz C: Gastroprotective and antioxidant effects of usnic acid on indomethacininduced gastric ulcer in rats. J Ethnopharmacol 2006, 103(1):59-65.

24. Halici M, Odabasoglu F, Suleyman H, Cakir A, Aslan A, Bayir Y: Effects of water extract of Usnea longissima on antioxidant enzyme activity and mucosal damage caused by indomethacin in rats. Phytomedicine 2005, 12(9):656-662.

25. Bayir Y, Odabasoglu F, Cakir A, Aslan A, Suleyman H, Halici M, Kazaz C: The inhibition of gastric mucosal lesion, oxidative stress and neutrophilinfiltration in rats by the lichen constituent diffractaic acid. Phytomedicine 2006, 13(8):584-590.

26. Laine L, Weinstein WM: Histology of alcoholic hemorrhagic "gastritis": a prospective evaluation. Gastroenterology 1988, 94(6):1254-1262.

27. Shimizu N, Watanabe T, Arakawa T, Fujiwara Y, Higuchi K, Kuroki T: Pentoxifylline accelerates gastric ulcer healing in rats: roles of tumor necrosis factor alpha and neutrophils during the early phase of ulcer healing. Digestion 2000, 61(3):157-164.

28. Dadzie-Mensah J, MPhil: Modulation of eicosanoids biosyntheses in vivo as a mechanism-based evaluation of putative anti-inflammatory plant extracts. Legon: University of Ghana; 2000.

29. Mota KS, Dias GE, Pinto ME, Luiz-Ferreira A, Souza-Brito AR, Hiruma-Lima CA, Barbosa-Filho JM, Batista LM: Flavonoids with gastroprotective activity. Molecules 2009, 14(3):979-1012.

30. Matsumoto M, Hara H, Chiji H, Kasai T: Gastroprotective effect of red pigments in black chokeberry fruit (Aronia melanocarpa Elliot) on acute gastric hemorrhagic lesions in rats. J Agric Food Chem 2004, 52(8):2226-2229.

31. Dekanski D, Ristic S, Mitrovic DM: Antioxidant effect of dry olive (Olea europaea $\mathrm{L}$.) leaf extract on ethanol-induced gastric lesions in rats. Mediterr J Nutr Metab 2009, 2:205-211.

32. La Casa C, Villegas I, de Alarcon la Lastra C, Motilva V, Martin Calero MJ: Evidence for protective and antioxidant properties of rutin, a natural 
flavone, against ethanol induced gastric lesions. J Ethnopharmacol 2000, 71(1-2):45-53.

33. Innocenti A, Gulcin I, Scozzafava A, Supuran CT: Carbonic anhydrase inhibitors. Antioxidant polyphenols effectively inhibit mammalian isoforms I-XV. Bioorg Med Chem Lett 2010, 20(17):5050-5053.

34. Ozturk Sarikaya SB, Topal F, Senturk M, Gulcin I, Supuran CT: In vitro inhibition of alpha-carbonic anhydrase isozymes by some phenolic compounds. Bioorg Med Chem Lett 2011, 21(14):4259-4262.

35. Senturk M, Gulcin I, Beydemir S, Kufrevioglu OI, Supuran CT: In Vitro inhibition of human carbonic anhydrase I and II isozymes with natural phenolic compounds. Chem Biol Drug Des 2011, 77(6):494-499.

doi:10.1186/1472-6882-12-247

Cite this article as: Nartey et al: Anti-ulcerogenic activity of the root bark extract of the African laburnum "Cassia sieberiana" and its effect on the anti-oxidant defence system in rats. BMC Complementary and Alternative Medicine 2012 12:247.

\section{Submit your next manuscript to BioMed Central and take full advantage of:}

- Convenient online submission

- Thorough peer review

- No space constraints or color figure charges

- Immediate publication on acceptance

- Inclusion in PubMed, CAS, Scopus and Google Scholar

- Research which is freely available for redistribution 